\title{
Firm Size, Commodity Price, and Interdependence Between Firm-Level Stock Prices: The Case of Norwegian Salmon Industry
}

\author{
Dengjun Zhang ${ }^{1}, \varnothing y s t e i n$ Myrland ${ }^{2}, \&$ Jinghua Xie $^{2}$ \\ ${ }^{1}$ Business School, University of Stavanger, Norway. \\ ${ }^{2}$ School of Business and Economics, UiT / The Arctic University of Norway, Norway. \\ Correspondence: Dengjun Zhang, Business School, University of Stavanger, 4036 Stavanger, Norway.
}

Received: August 12, 2016

Accepted: August 25, 2016

Available online: September 8, 2016

doi:10.11114/aef.v3i4.1864

URL: http://dx.doi.org/10.11114/aef.v3i4.1864

\begin{abstract}
This study aims to investigate the interdependence between stock prices of salmon firms listed at Oslo Stock Exchange and to evaluate how this correlation is affected by firm size and salmon commodity price. Technically, we apply the Johansen's approach (Johansen, 1991) to test cointegration between stock prices and between individual stock prices and commodity price. The time path of the long-run relationship is further examined by recursive estimations. During the sample period, we fail to confirm a common stochastic trend between the stock prices of salmon firms. This is partly explained by the various responses of firm-level stock prices to the leading firm' stock price, depending on firm size. This may also relate to the differences between salmon stock prices' responses to commodity price.
\end{abstract}

Keywords: stock price, commodity price, salmon, interdependence, cointegration

\section{Introduction}

Recent research typically focuses on the impact of commodity financialization on commodity prices and the impact of commodity prices on the stock market (Falkowski, 2011). The large increase in commodity price volatilities can attribute partially to commodities' financialization process (Tang \& Xiong, 2012). Over a long horizon, both stock and commodity prices are expected to move in a similar direction as both respond to future economic performances (Black et al., 2014). Therefore, the empirical issue is how the prices of commodities affect the firm-level stock prices. On the other hand, firm size may affect the response of firm-level stock price to commodity price changes. For example, price volatility influences less the large firms than the small firms within the same industry. Perez, Quiros, and Timmermann (2000) claimed that the asymmetries in the variation of small and large firms could be explained by the differences in stock prices' responses to changes in the underlying economic conditions. The knowledge about how commodity prices affect stock prices of the different size firms would aid our understanding of the relationships between those stock prices. This also has a particular implication for portfolio diversification across firms.

The impact of commodity price on stock market performances has been widely explored in the literature (Hammoudeh \& Li, 2005; Bjørnland, 2009; Miller \& Ratti, 2009; Du et al., 2011; Creti et al., 2014; Nordin et al., 2014; Zhang \& Asche, 2014). Most studies treated oil price as a proxy of commodity price and evaluated the impact of oil price on stock indices. For example, Zhang and Asche (2014) explored how oil price strengthens the interdependence between the Nordic stock markets. Sadorsky (2014) compared the dynamic correlations between emerging market stock prices and the prices of copper, oil, and wheat. However, the correlations between some small commodity prices and stock market indices are short of fundamentals.

For a particular industry, firm-level stock prices are expected to move in a similar direction. This means stock prices respond to a single, common, industry-based factor, although those prices have a random walk with drift components (Kasa, 1992). Among the factors shaping the industry of interest and hence affecting firm-level stock prices, commodity price is obviously the best candidate that relates to the common trend. However, commodity price has, in recent years, steadily moved to a high level of fluctuations, which may lead to heterogeneity between firms' responses to commodity price. Consequently, this probably causes several common stochastic trends between firm-level stock prices. Focusing on the US stock market, D'Antoni and Dean Detre (2014) provided the evidence that the returns between a broad agribusiness stock index and the S\&P 500 index are moderately correlated on positive return days. This may limit the benefit to include the agribusiness stock index in portfolio. They further suggested that a number of sub-assets class within the index might 
offer benefit to investors. When investors focus on firm-level stock prices, hedging and diversification strategies are based on the interdependence between the individual stock prices.

This study aims to investigate the interdependence between firm-level stock prices and the impact of commodity market price on that relationship. The case study is salmon firms listed at Oslo Stock Exchange, i.e. Marine Harvest ("MHG"), Lerøy Seafood ("LSG"), SalMar ("SALM"), and Grieg Seafood ("GSF"). Norway is the largest salmon producer in the world, which simulates the major firms to become publicly traded securities. Operations of those companies generally concentrate on salmon production, indicating the direct influence of salmon commodity price on firms' cash flows and earnings. Following the finance literature where cointegration is frequently applied to assess the degree of interdependence between financial markets (Dimpfl, 2013), we are to apply Johansen's (1991) cointegration techniques to test the interdependence between the four salmon firms' stock prices. However, the statistical relationship between stock prices may change in response to the volatile fundamentals (Serletis \& King, 1997; Black et al., 2014). The recursive estimation approach (Hansen \& Johansen, 1999; Juselius, 2006) is further employed to examine the evolvement of the interdependence between stock prices. The impact of salmon commodity price on stock prices is further examined by using a bivariate model. As salmon firm sizes vary (Asche et al., 2013), the interdependence between salmon firm stock prices and the role of salmon commodity price in the evolvement of the relationship is probably subject to firm sizes.

The remainder of the article is organized as follows. The next section briefly discusses the Norwegian salmon industry and salmon stock and market prices. The econometric methods are multivariate and bivariate unrestricted / restricted vector error correction (VEC) models and recursive estimations. After outlining the econometric approach, the empirical results of the analysis are presented. The conclusive remarks are given in the final section.

\section{Background}

During the past decades, salmon is among the most successful aquaculture species in terms of production growth. The global salmon production has increased from 12,000 tonnes in 1980 to over 2.4 million tonnes in 2011 (Asche et al., 2013). Among the producers, Norway holds a leading position in this industry. In 2013, Norway supplied 1.14 million tonnes salmon, which accounted for about $62 \%$ of the global production. Following the trend in the global salmon industry, a strong consolidation process has been taking place in Norway, resulting in a high concentration of the industry. In Norway, the top ten salmon companies made up about $71 \%$ of the total production based on provisional values in 2013. However, size differences between those salmon firms are obviously substantial. For example, the combined share of the top three companies (Marine Harvest, Lerøy Seafood, and SalMar) was much higher than the combined share of the remaining seven companies (60\% versus 11\%). Another characteristic of the Norwegian salmon industry is the process of internationalization as evidenced by the increasing production in Chile, the UK, and the North America. The degree of internationalization is parallel to firm size. For example, Marine Harvest represents the greatest share of the global salmon production with one-third production in other countries rather than Norway.

The growing salmon production accompanied with the boosting demand has simulated investment in the salmon industry and the relevant publicly traded securities. In 1997, PanFish became a listed company at Oslo Stock Exchange. PanFish acquired Marine Harvest in 2006, and changed the company name to Marine Harvest in 2007. Thus, 2007 was the first full year for the merged company. In 2014, Marine Harvest was further traded at New York Stock Exchange. Following the footsteps of Marine Harvest, a number of other salmon producers became publicly traded companies. Lerøy Seafood and SalMar listed at Oslo Stock Exchange in June 2002 and July 2007, respectively. This trend is also echoed by the small producers. For example, Grieg Seafood made its initial public offering on June 2007. Recently, Norway Royal Salmon became a publicly traded company in March 2011. However, in contrast to the above trend, Cermaq, a big salmon producer, delisted its shares from Oslo Stock Exchange in November 2014 after the company was acquired by Mitsubishi Corporation.

In this study, we will examine the interdependence between the stock prices of Marine Harvest ("MHG"), Lerøy Seafood ("LSG"), SalMar ("SALM"), and Grieg Seafood ("GSF"). While Cermaq is deleted from the sample due to its privatization, the exclusion of Norway Royal Salmon is related to its short sample period. The sample companies are composed of the top three producers (MHG, LSG, and SALM) and one small producer (GSF) and well represent the whole Norwegian salmon industry. The comparison between the responses of the large and the small firms to salmon commodity price can reveal the impact of company size on market interactions. The sample period starts from 2007 in which LSG and GSF became publicly traded securities and MHG got a significant increase in operating revenue due to the acquisition in 2006. The sample period ends in March 2013 in order to get consistent data, since it is the date on which the salmon commodity price was substantially modified, see more below.

The salmon commodity price used in this paper is the weekly price paid by exporters to Norwegian salmon famers for fresh and gutted salmon of superior quality. The transactions are above at least 40 tonnes and are made between exporters and salmon farmers outside the exporters' own group. This price series is provided by NOS Clearing ASA and has been widely used in the literature as a proxy of salmon commodity price (Asche \& Guttormsen, 2001; Oglend \& Sikveland, 
2008; Asheim et al., 2011; Oglend, 2013). Since March 2013, NOS Clearing ASA replaced salmon farm-level price with an averaged export price. Accordingly, to keep data consistent, the sample period is ended in March 2013. In addition, the interrelations between stock prices of the biggest salmon company, Marine Harvest, and other companies may change after 2013, as Marine Harvest has been traded at New York Stock Exchange since 2014 and would then bear the systematic risks in two stock markets.

Before merging the data, stock prices are adjusted for historical corporate actions such as stock split, reverse stock split, dividends, distributions, and right offerings. The daily stock prices are aggregated to weekly frequency by taking means of the daily prices within a particular week. Afterwards, the weekly stock prices are combined with the weekly salmon commodity price (hereafter "NOS"). Our data cover week 25 in 2007 to week 13 in 2013, totally 302 observations.

Summary statistics for the four salmon stock prices and NOS are reported in Table 1. Comparisons between mean and standard deviation for each price can roughly reflect the movements of those price levels. Among the stock prices, MHG and GSF are relatively more stable than the other two prices, which are also more volatile than salmon commodity price. After normalizing the time series with respect to the mean of the first four weeks, we further plot the five price series in figure 1. During the sample period, the four stock prices seem to move along with each other very well in spite of a high level of fluctuations individually. Figure 1 is also quite evident of the co-movements between the four stock prices and salmon commodity price for some sub-periods.

Table 1. Descriptive Statistics of Price Variables

\begin{tabular}{lcccc}
\hline Variable & Mean & Maximum & Minimum & $\begin{array}{c}\text { Standard } \\
\text { Deviation }\end{array}$ \\
\hline$P_{M H G}$ (Marine Harvest) & 41.94 & 72.14 & 10.08 & 14.98 \\
$P_{L S G}($ Lerøy Seafood) & 112.27 & 193.25 & 41.23 & 33.56 \\
$P_{S A L M}($ SalMar $)$ & 42.27 & 67.50 & 22.20 & 10.58 \\
$P_{G S F}($ Grieg Seafood) & 12.34 & 24.00 & 3.06 & 5.37 \\
$P_{N O S}$ (Salmon commodity price) & 29.85 & 33.60 & 18.17 & 6.31 \\
\hline
\end{tabular}

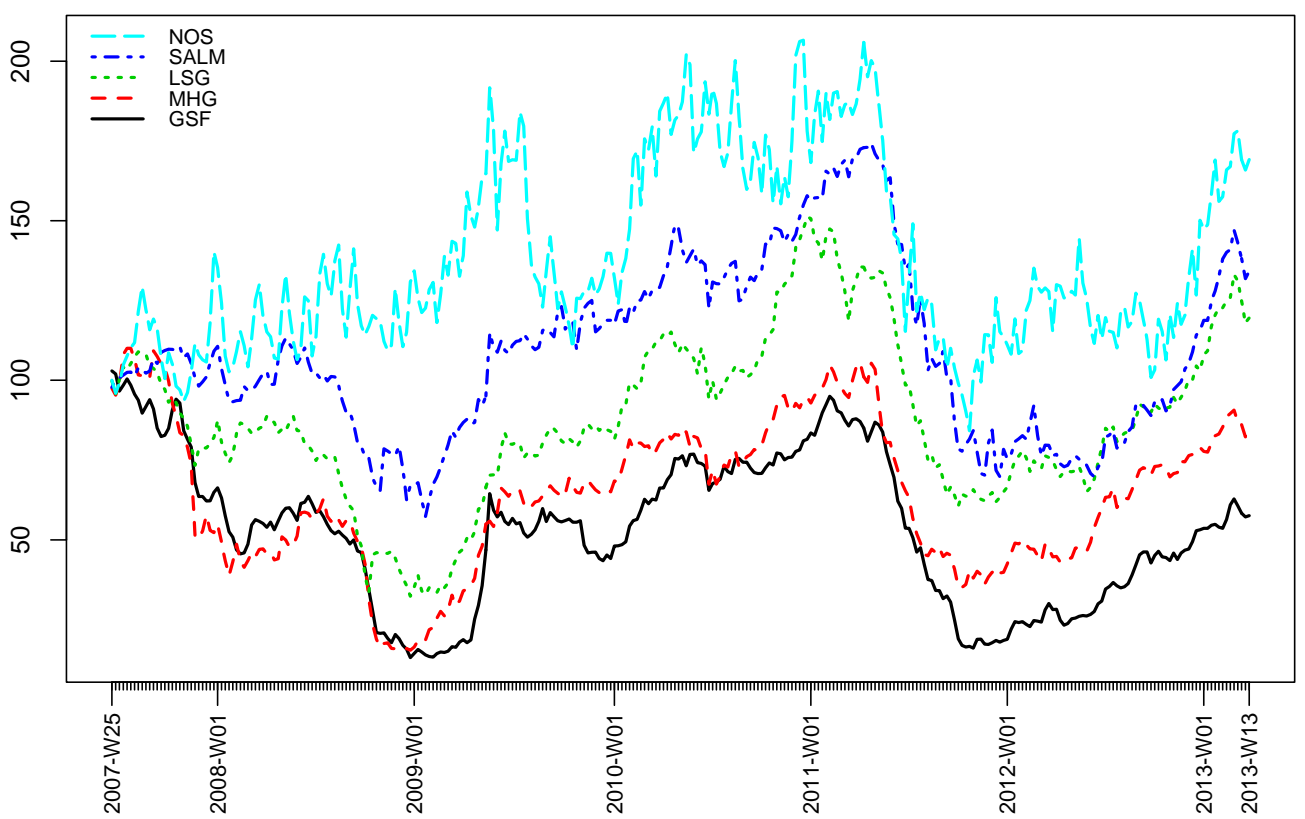

Figure 1. Weekly Salmon Stock Price and Salmon Price: 2007-2013 (week 25 28 of $2007=100$ ). 


\section{Methodology}

In this study, Johansen's (1991) econometric techniques are applied to test the interdependence between the four salmon stock prices. The Johansen approach has been widely applied in the finance literature to explore the independence between international stock markets (Kasa, 1992; Dağli et al., 2012; Zhang \& Asche, 2014) and between stock prices and commodity prices (Hammoudeh \& Li, 2005; Miller \& Ratti, 2009; Dengjun, 2015).

The Johansen's procedure is based on an unrestricted vector error correction (VEC) model represented by:

$$
\ln P_{t}=\quad \ln P_{t 1}+\sum_{i=1}^{g} \quad i \quad \ln P_{t i}+e_{t}
$$

where $\ln \boldsymbol{P}$ is a $4 \times 1$ vector of four stock prices in logarithm form, $\Delta$ is the first-order difference operation, $g$ represents the number of lags for the first-order differenced variables, and $\boldsymbol{e}_{\boldsymbol{t}}$ is a vector of i.i.d. error terms with zero mean. The matrices $\Gamma_{i}(4 \times 4)$ and $\Pi(4 \times 4)$ are the short-run parameters and the long-run "level solution" to the price vector, respectively. Noting the stationarity of all first-order differenced variables, the rank of $\Pi(0 \leq r \prec 4)$ determines how many linear combinations of $\ln \boldsymbol{P}_{t-1}$ are stationary. If the rank of $\Pi$ does not equal to zero, we can factorize $\Pi, \Pi=\alpha \beta$, where the matrix $\alpha(4 \times r)$ and $\beta(4 \times r)$ contain the adjustment parameters and the long run parameters, respectively. If the rank of $\Pi$ equals 3 (equivalently, 1 common stochastic trend), the stochastic trends of the four stock prices are shared in the vector process.

The standard cointegration analysis fails to take account of the evolvement of stochastic trends among the multivariate model (Serletis \& King, 1997). When estimating (1), the underlying assumption is that the space of the cointegrating relationships is stable during the sample period. As the degree of market interdependence deepens, the number of cointegrations should increase to reflect the changes in the market (Rangvid, 2001). On the other hand, the dynamic features of the economic foundations underlying the firm-level stock prices may cause changes in the cointegration space over time (Black et al., 2014). Accordingly, the recursive estimation methodology is applied to test evolution of the cointegration space in the multivariate system. This methodology is introduced by Hansen and Johansen (1999) and is recently applied by Büyükşahin et al. (2007) and Zhang and Asche (2014) to test the time path of cointegrating space in the international stock markets. The recursive cointegration method is performed in two steps. First, the short run parameters of the unrestrictive VEC model are estimated using the whole sample. In the second stage, after keeping the short run parameters constant to the full sample value, the long run parameters are re-estimated using progressively more data.

For a sample with $T$ observations, the baseline period is set to be 1:( $\left.T_{1}-1\right)$, and the recursions are defined by adding more observations. Thus, the recursions are performed for the sub-samples $1: t$, where $t=T_{1}, T_{1}+1, \ldots, T$. For each recursion, the statistic value of the cointegration test is kept and then constitutes a set of time series. Considering the finite-sample bias of Johansen's tests (Cheung \& Lai, 1993), a finite-sample correction is applied to adjust the test statistics, which is further normalized by the critical values. The comparison between the test statistics and unity reflects the degree of the interdependence between the four stock prices.

As discussed early, the relationship between the four stock prices is probably related to their responses to changes in salmon commodity price. Accordingly, a bivariate Johansen test is employed to test the cointegration between individual stock prices and salmon commodity price. The equation (1) is then modified to take $\ln \boldsymbol{P}$ as a $2 \times 1$ vector. Since the existence of three cointegrating vectors for the 4 -dimensional system implies the cointegrating pairwise variables, the Johansen test is further applied to evaluate the pairwise long-run relationships in the system of the four stock prices. This can also provide evidence of relationship between firm size and stock price's response to market changes.

Turing to the long-run parameter, we are to evaluate the long-run equilibrium between the multivariate or bivariate model. Accordingly, we need to factorize $\Pi, \Pi=\alpha \beta^{\prime}$. However, the decomposition of $\Pi=\alpha \beta^{\prime}$ is not unique. For example, we can define $\alpha^{*}=\alpha \gamma$ and $\beta^{*}=\beta\left(\gamma^{\prime}\right)^{-1}$, where $\gamma$ is an arbitrary $r \times r$ nonsingular matrix. Here, $\alpha^{*} \beta^{*}$, gives the same $\Pi$ matrix. For a multivariate model, the theoretical restrictions can be imposed on the cointegration to obtain a unique solution for the long run parameters (Zhang et al., 2014; Dengjun, 2015; Zhang, 2015). In our case of a 4-dimensional system, the existence of three cointegrating expressions can facilitate to normalize each cointegration in terms of one base, for example, MHG. For a bivariate model with one cointegration, one of the prices can be used to normalize the vector. Taking the bivariate model between GSF and NOS as an example, the restrictive VEC model is in the form (firstdifference variables lagged more than one period are suppressed):

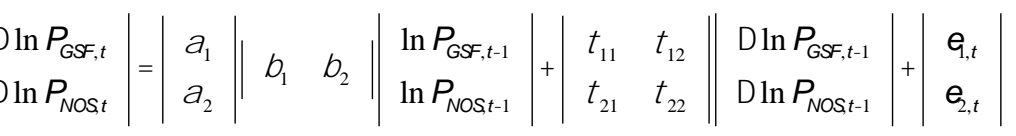


where restriction is set on either $\beta_{1}$ or $\beta_{2}$. As the variables are in logs, the estimated long-run normalized coefficients are interpreted as elasticities.

\section{Discussion and Analysis}

\subsection{Integration Analysis of Individual Series}

For the cointegration analysis, the first step in the empirical analysis is to investigate the order of integration of the individual price series. We perform the Augmented Dickey Fuller (ADF) test and KPSS test (Kwiatkowski et al., 1992) for the (non)stationarity of the logarithmic prices. The ADF test has a null that the variable has a unit root. By contrast, the KPSS approach has the null hypothesis of stationary series. Thus, those two methods are intended to complement each other and can provide robust results about the presence of unit roots.

The test outcomes are reported in Table 2, which reflects that, at the 5\% level of confidence, the null hypothesis of unit root cannot be rejected for each price series by the ADF tests but the null hypothesis of stationary series is consistently rejected by the KPSS tests. This indicates that each log-transformed price contains a unite root, i.e. first-difference stationary. This is further confirmed by the test on the differenced series. Table 2 clearly shows that, for each first differenced price series, the ADF tests reject the null hypothesis and the KPSS tests fail to reject the null hypothesis, indicating the raw series are first-difference stationary.

Table 2. Unit Root Tests

\begin{tabular}{cccccc}
\hline \multirow{2}{*}{ Variable } & \multicolumn{2}{c}{ ADF } & & \multicolumn{2}{c}{ KPSS } \\
\cline { 2 - 3 } \cline { 5 - 6 } & Level & Difference & & Level & Difference \\
\hline $\ln P_{M H G}$ & -2.73 & $-5.25^{* *}$ & & $0.28^{* *}$ & 0.089 \\
$\ln P_{L S G}$ & -1.85 & $-6.08^{* *}$ & & $0.33^{* *}$ & 0.11 \\
$\ln P_{S A L M}$ & -1.41 & $-13.40^{* *}$ & & $0.48^{* *}$ & 0.12 \\
$\ln P_{G S F}$ & -2.34 & $-6.76^{* *}$ & & $0.29^{* *}$ & 0.097 \\
$\ln P_{\text {NOS }}$ & -2.22 & $-16.93^{* *}$ & & $0.65^{* *}$ & 0.055 \\
Critical Value $(5 \%)$ & -2.87 & -2.87 & & 0.146 & 0.146 \\
\hline
\end{tabular}

Note: (i) the order of lagged difference terms with a maximum order of 6; (ii) ${ }^{* *}$ indicates significance at the 5\% level.

Properties of the data generating processes dictate that the Johansen procedure is the appropriate method to test the cointegrations between the four stock price series and between individual stock prices and salmon commodity price.

\subsection{Cointegration Analysis for Stock Prices}

By using equation (1), we execute the Johansen test for the 4-dimensional multivariate model. The lag order for the differenced variables is chosen on the basis of the Akaike information criterion (AIC). The test results are reported in Table 3. Both the tract test and the maximum eigenvalue test are applied by assuming a deterministic trend in the cointegrating relationship (results are robust to excluding the trend variable).

Table 3. Johansen Test Statistics for the Multivariate System of Stock Prices

\begin{tabular}{ccccccc}
\hline \multicolumn{3}{c}{ Trace Test } & & \multicolumn{3}{c}{ Maximum Eigenvalue Test } \\
\cline { 6 - 7 } \cline { 5 - 6 } $\mathrm{H}_{\mathrm{o}}:$ & $\mathrm{H}_{\mathrm{a}}:$ & Trace Statistic & & $\mathrm{H}_{\mathrm{o}}:$ & $\mathrm{H}_{\mathrm{a}}:$ & Max-Eigen Statistic \\
\hline $\mathrm{r}=0$ & $\mathrm{r}=1$ & $88.59^{* *}$ & & $\mathrm{r}=0$ & $\mathrm{r} \geq 1$ & $39.66^{* *}$ \\
$\mathrm{r}=1$ & $\mathrm{r}=2$ & $48.92^{* *}$ & & $\mathrm{r} \leq 1$ & $\mathrm{r} \geq 2$ & $31.25^{* *}$ \\
$\mathrm{r}=2$ & $\mathrm{r}=3$ & 17.67 & & $\mathrm{r} \leq 2$ & $\mathrm{r} \geq 3$ & 13.90 \\
$\mathrm{r}=3$ & $\mathrm{r}=4$ & 3.76 & & $\mathrm{r} \leq 3$ & $\mathrm{r} \geq 4$ & 3.76 \\
\hline
\end{tabular}

Note: ${ }^{* *}$ indicates significance at the $5 \%$ level.

As shown in Table 3, the trace test results indicate two cointegrating vectors among the four firm-level stock prices at the $5 \%$ level of significance. For the maximum eigenvalue test, the null hypothesis of no more than one cointegration is rejected in favor of more than two cointegrations. However, the null hypothesis of no more than two cannot be rejected. Thus, the maximum eigenvalue test results also confirm the existence of two cointegrations among the four prices. Hence, the four stock prices are linked together by two cointegrating vectors, implying the existence of two shared stochastic trends in the four-dimensional system. The lower correlation among the stock prices can be used to justify the diversification of portfolios. 
Before proceeding to the next step, we recursively estimate the unrestrictive VEC model to explore the evolvement of the interdependence between the four price series. We choose the base period from week 25 of 2007 to week 21 of 2008 . The ending date is the week when the stock index locally peaks and hence approximates the starting point of the 2008 financial crisis in this market. Thus, the base period represents a relatively stable market. The recursions are defined for the subsamples 2007:week 25-2008:week 22, 2007:week 25-2008:week 23, .. , 2007:week 25-2013:week 13 (the whole sample).

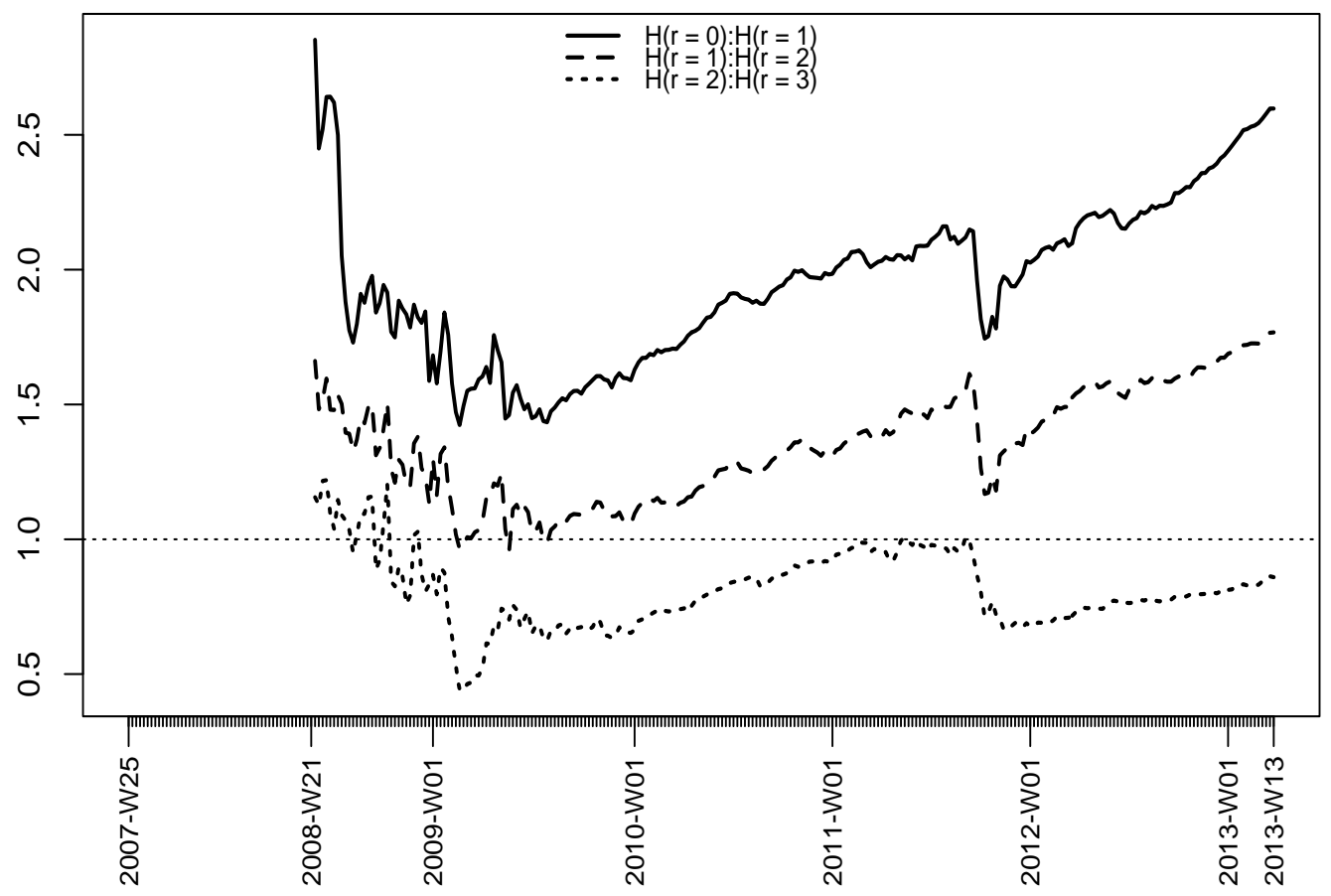

Figure 2. Normalized Trace Test Statistic Values (5\% significant level) from the Recursive Estimations.

Considering the more power of the trace test compared to the maximum eigenvalue test (Serletis \& King, 1997), we report the recursive test results in terms of the trace test in Figure 2. In the figure, the three lines represent the trace test statistics in terms of one, two, and three cointegrations, respectively. Since the test statistic values are normalized, the values above unity (the horizontal line) indicates the rejection of the null hypothesis. For each line, there are large changes in the test results through the sample period. In the early period, there are three cointegrations, indicating one stochastic trend among the price vector. Later, the three lines become more volatile and the line related to the test of three cointegrations is even below the horizontal unity line, indicating the rejection of one common stochastic trend. This may attribute to the 2008 financial crisis and/or the huge reduction in salmon commodity price. As of later 2009, each of the three statistic values presents an upward trend. The results even support the existence of three cointegrations at the 5\% level of confidence before the downturn of the trend. The upward trend is interrupted in the end of 2011 but is recovered very soon. This coincides with the pattern of salmon commodity price. As show in Figure 1, salmon commodity price experienced a large reduction in 2011, which may affect the salmon stock prices, depending on firm sizes.

In sum, the recursive test results provide evidence for two cointegrations through the sample period but not three cointegrations with the exception of several time points.

\subsection{The Impact of MHG on Other Stock Prices}

It is difficult to set restrictions on the multivariate VEC model to obtain pairwise relationships unless there is a common stochastic trend shared by the price series (see Asche et al., 1999; Zhang \& Asche, 2014). Therefore, we turn to the bivariate VEC model to examine the pairwise relationships between the salmon stock prices. Given the importance of Marine Harvest in this industry, we are more interested to examine the correlation between MHG and each of the other three price series. First, we test the cointegration between pairwise price series and report the results in Table 4 . 
Table 4. Bivariate Johansen Test Statistics (salmon stock prices versus MHG)

\begin{tabular}{|c|c|c|c|c|c|}
\hline \multicolumn{3}{|c|}{ Trace Test } & \multicolumn{3}{|c|}{ Maximum Eigenvalue Test } \\
\hline $\mathrm{H}_{0}:$ & $\mathrm{H}_{\mathrm{a}}:$ & $\begin{array}{c}\text { Trace } \\
\text { Statistic }\end{array}$ & $\mathrm{H}_{\mathrm{o}}:$ & $\mathrm{H}_{\mathrm{a}}:$ & $\begin{array}{c}\text { Max-Eigen } \\
\text { Statistic }\end{array}$ \\
\hline \multicolumn{6}{|c|}{$\ln P_{L S G}$ vs. $\ln P_{M H G}$} \\
\hline$r=0$ & $r=1$ & $32.31^{* *}$ & $r=0$ & $r \geq 1$ & $25.83^{* *}$ \\
\hline$r=1$ & $r=2$ & 6.47 & $\mathrm{r} \leq 1$ & $r \geq 2$ & 6.47 \\
\hline \multicolumn{6}{|c|}{$\ln P_{S A L M}$ vs. $\ln P_{M H G}$} \\
\hline$r=0$ & $\mathrm{r}=1$ & 20.91 & $\mathrm{r}=0$ & $r \geq 1$ & 16.79 \\
\hline$r=1$ & $r=2$ & 4.12 & $\mathrm{r} \leq 1$ & $r \geq 2$ & 4.12 \\
\hline \multicolumn{6}{|c|}{$\ln P_{G S F}$ vs. $\ln P_{M H G}$} \\
\hline$r=0$ & $r=1$ & $25.87^{* *}$ & $r=0$ & $r \geq 1$ & $239.49^{* *}$ \\
\hline$r=1$ & $r=2$ & 5.94 & $\mathrm{r} \leq 1$ & $r \geq 2$ & 5.94 \\
\hline
\end{tabular}

Note: ${ }^{* *}$ indicates significance at the $5 \%$ level.

The test results for the three pairwise price series are consistent between the trace test and the maximum eigenvalue test. The long-run relationship between LSG and MHG and between GSF and MHG are clearly verified by the two test results. However, the hypothesis of one cointegration between SALM and MHG is rejected. The test results are consistent with those from the multivariate model. Only in the situation in which there is a common stochastic trend in the multivariate system, all the prices are pairwise cointegrated (Stock \& Waston, 1988).

After imposing one normalization restriction on the cointegration vector ( $\beta$ in equation (2)), we can identify the bivariate system and qualify how MHG (the normalized variable) affects the other salmon stock prices. For the two cointegrating bivariate system, the restrictive VEC model is estimated and the results are reported in Table 5. The estimates of the longrun coefficients are substantially significant. Noting that the coefficient of MHG is normalized to one, the negative coefficients denote a positive long-run relationship. Our estimate results indicate that, in the long run, for a $1 \%$ increase in MHG price, the LSG and GSF prices would increase by $0.82 \%$ and $1.18 \%$, respectively. The less sensitivity of LSG to changes in MHG can attribute to its bigger size compared with GSF. The positive and significant coefficient of the trend variable in GSF -MHG system implies the declined impact of MHG on GSF, which may relate to a fast growing production of GSF during the sample period.

Table 5. Long-run Impact of MHG Price on other Salmon Stock Prices

\begin{tabular}{cccc}
\hline Variable & Coef. & Variable & Coef. \\
\hline $\ln P_{L S G}$ & 1 & $\ln P_{G S F}$ & 1 \\
$\ln P_{M H G}$ & $-0.82^{* * *}$ & $\ln P_{M H G}$ & $-1.18^{* * *}$ \\
& $(0.061)$ & & $(0.033)$ \\
Trend & -0.00045 & Trend & $0.0023^{* *}$ \\
& $(0.00030)$ & & $(0.00016)$ \\
Constant & -1.54 & Constant & 1.31 \\
\hline
\end{tabular}

Note: ${ }^{* *}$ and ${ }^{* * *}$ indicate significance at the $5 \%$ and $1 \%$ levels, respectively.

\subsection{The Impact of Salmon Commodity Price on Salmon Stock Prices}

Looking at the Figures 1 and 2, we might conclude that salmon commodity price can in part contribute to the evolvement of the interdependence between the four stock prices. For example, the salmon commodity price plunged to the lowest level at the end of 2011, which may be the driving force behind the downturn of the test statistic values. This is tested by undertaking the Johansen's approach for the pairwise price series of salmon commodity price and each of the salmon stock prices. The results are reported in Table 6 . 
Table 6. Bivariate Johansen Test Statistics (Salmon Stock Prices Versus Salmon Commodity Price)

\begin{tabular}{|c|c|c|c|c|c|}
\hline \multicolumn{3}{|c|}{ Trace Test } & \multicolumn{3}{|c|}{ Maximum Eigenvalue Test } \\
\hline $\mathrm{H}_{\mathrm{o}}$ : & $\mathrm{H}_{\mathrm{a}}:$ & $\begin{array}{c}\text { Trace } \\
\text { Statistic }\end{array}$ & $\mathrm{H}_{\mathrm{o}}$ : & $\mathrm{H}_{\mathrm{a}}:$ & $\begin{array}{c}\text { Max-Eigen } \\
\text { Statistic }\end{array}$ \\
\hline \multicolumn{6}{|c|}{$\ln P_{M H G}$ vs. $\ln P_{N O S}$} \\
\hline $\mathrm{r}=0$ & $r=1$ & 14.41 & $r=0$ & $r \geq 1$ & 9.32 \\
\hline $\mathrm{r}=1$ & $r=2$ & 5.09 & $\mathrm{r} \leq 1$ & $r \geq 2$ & 5.09 \\
\hline \multicolumn{6}{|c|}{$\ln P_{L S G}$ vs. $\ln P_{N O S}$} \\
\hline$r=0$ & $\mathrm{r}=1$ & 13.86 & $\mathrm{r}=0$ & $r \geq 1$ & 7.26 \\
\hline$r=1$ & $r=2$ & 6.59 & $r \leq 1$ & $r \geq 2$ & 6.59 \\
\hline \multicolumn{6}{|c|}{$\ln P_{S A L M}$ vs. $\ln P_{N O S}$} \\
\hline $\mathrm{r}=0$ & $r=1$ & $293.37^{* *}$ & $r=0$ & $r \geq 1$ & $288.26^{* *}$ \\
\hline$r=1$ & $r=2$ & 5.10 & $\mathrm{r} \leq 1$ & $r \geq 2$ & 5.10 \\
\hline \multicolumn{6}{|c|}{$\ln P_{G S F}$ vs. $\ln P_{N O S}$} \\
\hline $\mathrm{r}=0$ & $\mathrm{r}=1$ & $42.25^{* *}$ & $r=0$ & $r \geq 1$ & $36.97^{* *}$ \\
\hline $\mathrm{r}=1$ & $r=2$ & 5.28 & $r \leq 1$ & $r \geq 2$ & 5.28 \\
\hline
\end{tabular}

Note: ${ }^{* *}$ indicate significance at the $5 \%$ level.

For the four pairwise relationships, the existence of one cointegration vector is confirmed in SALM - NOS and GSF NOS by both trace test and maximum eigenvalue test. The lack of cointegration between MHG and NOS and between LSG and NOS indicates that salmon commodity price does not affect the financial market performances of LSG and MHG, at least in the long run. Thus, we confirm the hypothesis of a strong and direct relationship between commodity price and stock prices of the small firms but not the large firms. Another reason to explain the empirical findings is related to the level of internationalization of those firms. In terms of plant locations, MHG and LSG are more internationalized than SALM and GSF, which may lead to the lack of correlation between their share prices and salmon commodity price. Heterogeneity between those stock prices' responses to changes in the commodity price may reduce the number of cointegrating relationships in the multivariate system.

After normalizing the cointegration vector with respect to NOS, we estimate the long-run parameters for the two bivariate models (Table 7). The results show that GSF is more sensitive to a percentage changes in salmon commodity price than SALM (1.46\% versus $0.95 \%)$. Since SALM's production is about three times GSF's production, we confirm that the small company is more sensitive to salmon commodity price changes. This further relates to the theoretical hypothesis that the incentive to undertake research for equity misprizing is greater for the large firms than for the small firms, given the search costs are the same across firms of different sizes (Maish \& Maish, 2004). Only GSF is responsive to both the market leading company (MHG) and salmon commodity price. Like the GSF-MHG system, the relationship between GSF and salmon commodity price becomes weak regarding the positive and significant coefficient of the trend variable. This conclusion also can apply to relationship between SALM and salmon commodity price.

Table 7. Long-Run Impact of Salmon Commodity Price on Salmon Stock Price

\begin{tabular}{lccc}
\hline Variable & Coef. & Variable & Coef. \\
\hline $\ln P_{S A L M}$ & 1 & $\ln P_{G S F}$ & 1 \\
$\ln P_{N O S}$ & $-0.95^{* * *}$ & & $-1.46^{* * *}$ \\
& $(0.065)$ & $\ln P_{N O S}$ & $(0.39)$ \\
Trend & $0.00040^{* * *}$ & & $0.0028^{* *}$ \\
& $(0.00015)$ & Trend & $(0.00089)$ \\
Constant & -0.58 & Constant & 1.79 \\
\hline
\end{tabular}

Note: ${ }^{* *}$ and ${ }^{* * *}$ indicate significance at the $5 \%$ and $1 \%$ levels, respectively.

Finally, it is very interesting and worth to explore how stock price and commodity price respond to the deviation in the 
long-run relationship. Thus, we turn to weak exogeneity test. In the $\alpha$ vector of equation (2), an insignificant adjustment coefficient implies the relevant variable is "weakly" exogenous, and would not react to long-run disequilibrium in the price linkage. The test results (available upon request) show that we fail to reject the hypothesis of weak exogeneity for stock prices in the two bivariate models. However, this hypothesis is rejected for salmon commodity price. These results are not too surprising, considering that commodity price is more determined by short-term demand and supply shocks.

\section{Conclusion}

This study examined the evolvement of the interdependence between four salmon stock prices at Oslo Stock Exchange, i.e. Marine Harvest ("MHG"), Lerøy Seafood ("LSG"), SalMar ("SALM"), and Grieg Seafood ("GSF"). The sample period is from 2007 to 2013. This is a period concerning the 2008 financial crisis and severe falls in salmon commodity price in 2008 and 2011. Changes in commodity price have a direct impact on the firms' current and expected cash flows, which are assumed to be the main driving forces underling the publicly traded firms' performances (Vuolteenaho, 2002). However, the large firms may own a stronger ability to manage commodity price volatility than those small firms, implying the different responses of stock prices to commodity price changes.

We first applied the Johansen's (1991) cointegration techniques to evaluate the interdependence between the four firmlevel stock prices. The empirical results present evidence of two cointegrations in the 4-dimensional multivariate system during the whole sample period. This means there are two stochastic common trends combining the four integrated stock prices together, implying the potential benefits from portfolio diversification across those firms. The weak interdependence between the four stock prices is probably related to the cointegrating space of the pairwise variables. Results from the bivariate Johansen model indicate the long-run relationship between MHG and LSG and between MHG and GSF but not between SALM and MHG. The normalized cointegrations further show a stronger impact of MHG on the small firm (GSF) than on the large firm (LSG).

The time path of the relationship between the firm-level stock prices is evaluated, by recursively estimating the Johansen model. The recursive estimations start from the middle of 2008 and provide the evidence of three cointegrations (i.e. one stochastic trend) in the several time points during the early period. Later, the test statistic values become more volatile and the existence of three cointegrations can be firmly rejected, which may relate to the 2008 financial crisis and the dramatic falls in commodity price. After that short dynamic period, the test values for null hypothesis of two cointegrations (alternative hypothesis of three cointegrations) have a steady upward trend with the peak at the end of 2011. The downturn point in the test statistic values follows the falls in salmon commodity price. Accordingly, the impact of salmon commodity price on salmon stock prices is further tested. While both SALM and GSF are cointegrated with salmon commodity price, respectively, MHG and LSG do not respond to salmon price. Relating the empirical findings to firm sizes, we can claim that a strong and direct long-run relationship exhibits between small firms and commodity price but not between large firms and commodity price. For the cointegrations regarding the small firms, the relatively smaller firm (GSF) is more sensitive to changes in commodity price.

The existence of two common stochastic trends between the salmon firms' stock prices implies that investors with a long holding period probably benefit from portfolio diversification across those firms. The market price of salmon can be used to predict the market performance of small salmon firms but not to predict that of large firms, which are probably exposed more to the systemic risk, an empirical matter requiring further studies.

\section{References}

Asche, F., \& Guttormsen, A. G. (2001). Patterns in the relative price for different sizes of farmed fish. Marine Resource Economics, 16(3), 235-247. http://dx.doi.org/10.1086/mre.16.3.42629321

Asche, F., Bremnes, H., \& Wessells, C. R. (1999). Product aggregation, market integration, and relationships between prices: an application to world salmon markets. American Journal of Agricultural Economics, 81(3), 568-581. http://dx.doi.org/10.2307/1244016

Asche, F., Roll, K. H., Sandvold, H. N., Sørvig, A., \& Zhang, D. (2013). Salmon aquaculture: Larger companies and increased production. Aquaculture Economics \& Management, $17(3), \quad 322-339$. http://dx.doi.org/10.1080/13657305.2013.812156

Asheim, L. J., Dahl, R. E., Kumbhakar, S. C., Oglend, A., \& Tveterås, R. (2011). Are prices or biology driving the shortterm supply of farmed salmon?. Marine Resource Economics, 26(4), 343-357.http://dx.doi.org/10.5950/0738-136026.4.343

Bjørnland, H. C. (2009). Oil price shocks and stock market booms in an oil exporting country. Scottish Journal of Political Economics, 56(2), 232-254. http://dx.doi.org/10.1111/j.1467-9485.2009.00482.x

Black, A. J., Klinkowska, O., McMillan, D. G., \& McMillan, F. J. (2014). Forecasting stock returns: Do commodity prices help? Journal of Forecasting, 33(8), 627-639. http://dx.doi.org/10.2139/ssrn.2467095 
Büyükşahin, B., Haigh, M. S., \& Robe, M. A. (2007). Commodities and equities: A "Market of One"? Journal of Alternative Investments, 12(3), 76-95. http://dx.doi.org/10.1108/afr-06-2013-0027

Cheung, Y. W., \& Lai, K. S. (1993). Finite-sample sizes of Johansen's likelihood ratio tests for cointegration, Oxford Bulletin of Economics and Statistics, 55(3), 313-328. http://dx.doi.org/10.1111/j.1468-0084.1993.mp55003003.x

Creti, A., Joëts, M., \& Mignon, V. (2013). On the links between stock and commodity markets' volatility. Energy Economics, 37, 16-28. http://dx.doi.org/10.1016/j.eneco.2013.01.005

D’Antoni, J. M., \& Dean, D. J. (2014). Are agribusiness stocks an investor safe haven?. Agricultural Finance Review, 74(4), 522-538.

Dağli, H., Sivri, U., \& Bank, S. (2012). International portfolio diversification opportunities between Turkey and other emerging markets. International Journal of Trade and Global Markets, 5(1), 4-23. http://dx.doi.org/10.1504/ijtgm.2012.045573

Dengjun, Z. (2015). Interdependence between Nordic stock markets and financial cooperation. Review of Accounting and Finance, 14(2), 172-188. http://dx.doi.org/10.1108/RAF-03-2013-0036

Dimpfl, T. (2014). A note on cointegration of international stock market indices. International Review of Financial Analysis, 33, 10-16. http://dx.doi.org/10.1016/j.irfa.2013.07.005

Du, X., Hayes, D. J., \& Yu, C. (2010). Dynamics of biofuel stock prices: A Bayesian approach. American Journal of Agricultural Economics, 93(2), 418-425. http://dx.doi.org/10.1093/ajae/aaq157

Falkowski, M. (2011). Financialization of commodities. Contemporary Economics, 5(4), 4-17. http://dx.doi.org/10.5709/ce.1897-9254.24

Hammoudeh, S., \& Li., H. (2005). Oil sensitivity and systematic risk in oil-sensitive stock indices. Journal of Economics and Business, 57, 1-21. http://dx.doi.org/10.1016/j.jeconbus.2004.08.002

Hansen, H., \& Johansen, S. (1999). Some tests for parameter constancy in cointegrated VAR-models. Econometrics Journal, 2(2), 306-333. http://dx.doi.org/10.1111/1368-423X.0003

Johansen, S. (1991). Estimation and hypothesis testing of cointegration vectors in Gaussian vector autoregressive models. Econometrica, 59(6), 1551-1580. http://dx.doi.org/10.2307/2938278

Juselius, K. (2006). The cointegrated VAR model: econometric methodology and macroeconomic applications, Oxford University Press, Oxford.

Kasa, K. (1992). Common stochastic trends in international stock markets. Journal of Monetary Economics, 29(1), 95124. http://dx.doi.org/10.1016/0304-3932(92)90025-W

Kwiatkowski, D., Phillips, C. B., Schmidt, P., \& Shin, Y. (1992). Testing the null hypothesis of stationarity against the alternative of a unit root: How sure are we that economic time series have a unit root? Journal of Econometrics, 54(1), 159-178. http://dx.doi.org/10.1016/0304-4076(92)90104-Y

Masih, R., \& Masih, A. M. M. (2004). Common stochastic trends and the dynamic linkage driving European stock markets: Evidence from pre- and post-October 1987 crash eras. European Journal of Finance, 10(1), 81-104. http://dx.doi.org/10.1080/13518470110040591

Miller, J. I., \& Ratti, R. A. (2009). Crude oil and stock markets: stability, instability, and bubbles. Energy Economics, 31, 559-568. http://dx.doi.org/10.1016/j.eneco.2009.01.009

Nordin, S., Nordin, N., \& Ismail, R. (2014). The impact of palm oil price on the Malaysian stock market performance. Journal of Economics and Behavioral Studies, 6(1), 1-9.

Oglend, A. (2013). Recent trends in salmon price volatility. Aquaculture Economics \& Management, 17(3), $281-299$. http://dx.doi.org/10.1080/13657305.2013.812155

Oglend, A., \& Sikveland, M. (2008). The behaviour of salmon price volatility. Marine Resource Economics, 23(4), 507526. http://dx.doi.org/10.1086/mre.23.4.42629677

Perez-Quiros, G., \& Timmermann, A. (2000). Firm size and cyclical variations in stock returns. The Journal of Finance, 55(3), 1229-1262. http://dx.doi.org/10.1111/0022-1082.00246

Rangvid, J. (2001). Increasing convergence among European stock markets? A recursive common stochastic trends analysis. Economics Letters, 71(3), 383-389. http://dx.doi.org/10.1016/S0165-1765(01)00361-5

Sadorsky, P. (2014). Modeling volatility and correlations between emerging market stock prices and the prices of copper, oil and wheat. Energy Economics, 43, 72-81. http://dx.doi.org/10.1016/j.eneco.2014.02.014 
Serletis, A., \& King, M. (1997). Common stochastic trends and convergence of European Union stock markets. The Manchester School, 65(1), 44-57. http://dx.doi.org/10.1111/1467-9957.00042

Stock, J. H., \& Watson, M. W. (1988). Testing for common trends. Journal of the American Statistical Association, 83(404), 1097-1107. http://dx.doi.org/10.1080/01621459.1988.10478707

Tang, K., \& Xiong, W. (2012). Index investment and the financialization of commodities. Financial Analysts Journal, 68(5), 54-74. http://dx.doi.org/10.2469/faj.v68.n6.5

Vuolteenaho, T. (2002). What drives firm - level stock returns?. The Journal of Finance, 57(1), $233-264$. http://dx.doi.org/10.1111/1540-6261.00421

Zhang, D. (2015). The trade effect of price risk: A system wide approach. Empirical Economics, 48(3), $1149-1167$. http://dx.doi.org/10.1007/s00181-014-0818-6

Zhang, D., \& Asche, F. (2014). The oil price shocks and Nordic stock markets. International Journal of Trade and Global Markets, 7(4), 300-315. http://dx.doi.org/10.1504/IJTGM.2014.067260

Zhang, D., Asche, F., \& Oglend, A. (2014). Ethanol and trade: An analysis of price transmission in the U.S. market. Energy Economics, 42, 1-8. http://dx.doi.org/10.1016/j.eneco.2013.11.012

\section{(cc) $\mathrm{BY}$}

This work is licensed under a Creative Commons Attribution 3.0 License. 